tioned telescope is such that images of the faintest-known isolated stars can (with the aid of a powerful magnifying glass) be plainly seen on a photographic plate exposed for less than five minutes in the focus. When this instrument is turned to the sun all known metals are melted and vaporized. A circular hole equal in size to the sun's focal image is almost instantly formed in a thin plate of sheet-iron held in the focus; by taking a much thicker piece the vaporization of the boiling-iron image of the sun (held in place by capillary action with the bordering plate of cold iron) can be observed at leisure until a hole is again formed.

To obtain a known value of $T$ for a measured value of $D$ the aperture of this mirror was gradually reduced (by means of circular openings, of different diameters, cut in cardboards placed centrally over the mirror) until a strip of platinum plate could just be melted when held in the focal plane. With the sun at $54^{\circ}$ zenith distance, in a clear atmosphere, the corresponding diameter was found to be eighteen inches.

Neglecting for the present the corrections due to aberrations and absorptions in the telescope and in the atmosphere, we have the following approximate values for substitution in formulas (4), (6) and (7):

$$
\begin{aligned}
D & =18.0 \text { in. } \\
d & =0.337 \mathrm{in} . \\
\left(\frac{r}{r_{0}}\right)^{2} & =44000 \\
T & =2000^{\circ} \mathrm{C} .
\end{aligned}
$$

The uncorrected results are, therefore,

Absolute temperature of space $=t=0^{\circ} .7 \mathrm{C}$.

Effective surface temperature of the sun $=$

$t_{0}=30800^{\circ} \mathrm{C}$.

The instrumental corrections (due mostly to absorption at the silver surface of the mirror) increase the value of $t$ from $0^{\circ} .70$ to $0^{\circ} .75$. The effect of atmospheric absorption on the intensity of ether vibrations must next be considered. My information on this subject is based upon a long series of photographic observations (on certain fixed stars) which I made, reduced and discussed more than sixteen years ago; the work (8vo, pp. 89) was published in 1893 under the title "Terrestrial Atmospheric Absorption of the Photographic Rays of Light" and forms No. 3 of "Contributions from the Lick Observatory." The tabular data on page 86 of this work give, for $54^{\circ}$ zenith distance, the intensity (or brightness) 0.61 , the brightness at the zenith being unity. If the temperature of the sun's focal image varies according to the same law, the value of $t$ is increased from $0^{\circ} .75$ to $1^{\circ} .23$ in the zenith; this value must, finally, be further increased by a still undetermined correction for absorption in the zenith; if we assume a one-fourth increase in the temperature due to this cause we have finally

Absolute temperature of space $=1^{\circ} .5 \mathrm{C}$.

Effective surface temperature of the sun

$$
=66000^{\circ} \mathrm{C} \text {. }
$$

It should be explicitly stated that the formulas are derived for the theoretical case of the earth without an atmosphere, or of observations made in free space. In actual observations $T$ denotes the rise in temperature above the temperature of the surrounding medium and, therefore, is equal to the absolute temperature of the sun's focal image minus the absolute temperature of the air at the place of observation.

J. M. SchaEberLE

ANN ARBor,

November 24, 1907

\section{A NOISELESS ROOM FOR SOUND EXPERIMENTS}

For many experiments in laboratories of physics, physiology and psychology a place is needed from which all, or nearly all, external sound can be excluded. An absolutely noiseless room opens up numerous new possibilities of research, especially in the fields of sound physiology and psychology. For this reason rooms have been constructed in many laboratories, but all the attempts to produce a noiseless room that are known to the writer are more or less unsuccessful, with the exception of the room to be described here.

The room to which reference is made is in the Physiological Institute of the University of Utrecht, Holland. It has been constructed under the direction and has been used by Professor H. Zwaardemaker, to whom I am in- 
debted for permission to publish the present description. ${ }^{1}$

The room is located on the top story of the laboratory building devoted to physiology. This floor of the building is little used, except for the sound room, and there are, consequently, few footsteps and other noises in the immediate neighborhood of the room. The location of the room at a distance from the street prevents to some extent the transmission of vibrations and jars of the street traffic.
A vertical section of the room from north to south is given in the accompanying figure. It will be seen that in the construction a small room has been formed to the south of the sound room. The ceiling of the small room is the roof of the building. The roof has been cut to form a window which admits light and air. The small room has been constructed with walls nearly as sound-proof as the larger room, and for some work may be used as an additional place for sound experi-

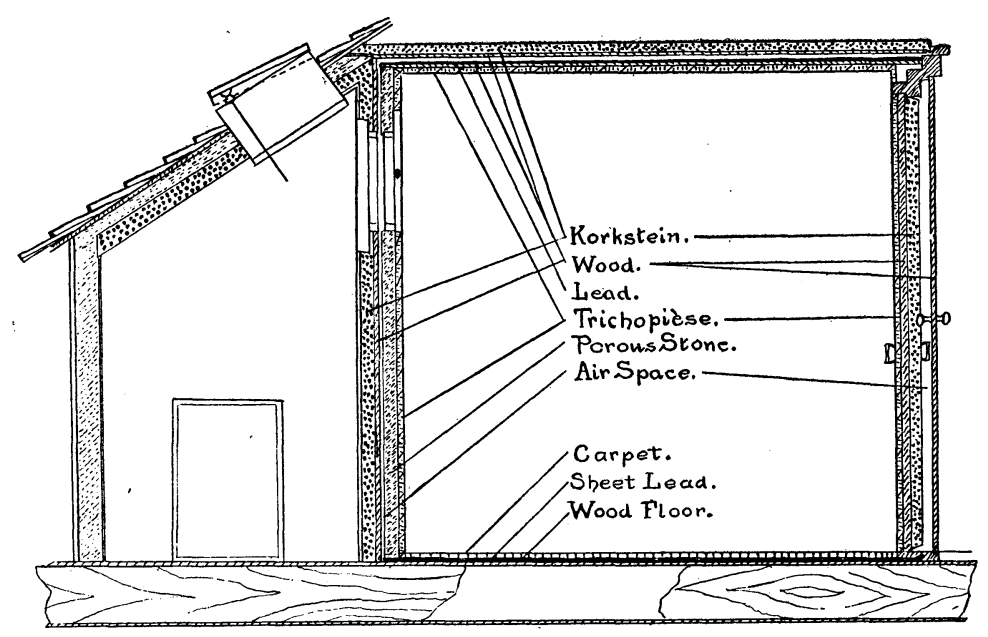

Fra. 1

Moreover, the room is an inside one, separated from the building walls by other rooms or a corridor, although in its construction, as will be noted below, provision is made for thorough ventilation and the entrance of sunlight. The other rooms of the laboratory on the same floor are comparatively little used, and by surrounding the sound room they help to isolate it.

${ }^{1}$ At the International Physiological Congress, Heidelberg, August, 1907, Professor Zwaardemaker read a description of the room and showed lantern slides of the plans of construction. Later, the writer had an opportunity of examining the room in the laboratory at Utrecht. A full description of the construction is to be published in the Zeitschrift $f$. Ohrenheilkunde. The proof of this article was in the writer's hands at the time of writing the present account. ments. When closed, it also serves to act as a dead air space between the larger room and the building wall and roof.

The inside measurements of the sound room are as follows: Length, $228 \mathrm{~cm}$; width, 220 cm.; height, $228 \mathrm{~cm}$.

The sides of the room are built of six layers. From the inside outwards the layers are as follow: (1) Trichopièse, about $5 \mathrm{~cm}$. thick. This is a felt-like material made of horse hair, and from experiments it has been found to have very low coefficients of conduction and reflection of sound. This layer is covered with a net on the inner side (to keep the hair from falling) and then fastened with nails to the second layer, which is more stable. (2) Porous stone, $7.5 \mathrm{~cm}$. thick. This part of the wall does not rest directly on the floor, but is isolated from the floor by a layer of sheet lead, 
$3 \mathrm{~mm}$. thick. Next there is (3) a dead air space from 2 to $3 \mathrm{~cm}$. thick. Layer 4 is a wood partition, 2.5 c.m. thick. The outermost layer (6) is a special composition of ground cork, Korkstein, $6 \mathrm{~cm}$. thick. The outer surface of the last layer is plastered, probably mainly for appearance. The space between layers 4 and 6 is filled with a mixture of ground cork and sand. The thickness of this mixture is $4 \mathrm{~cm}$. The total thickness of the walls is, therefore, about 11 inches.

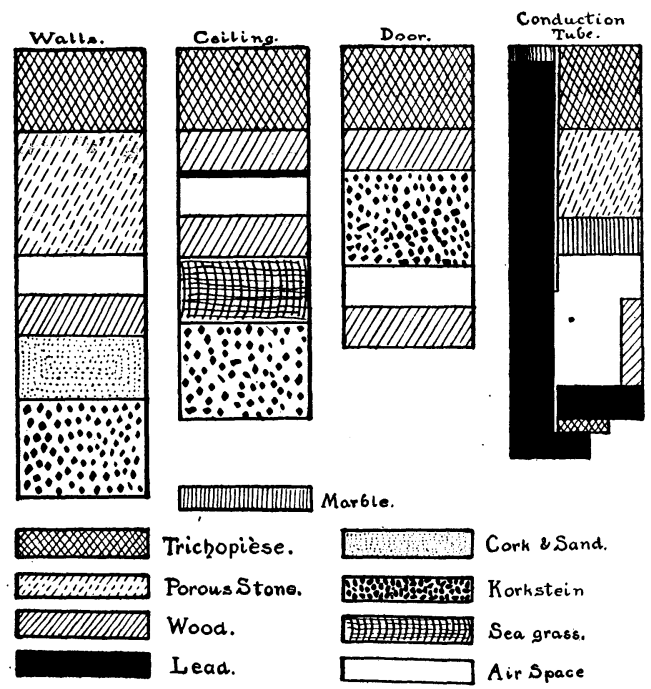

FIg. 2

The ceiling is more simply made, but it has an analogous "double-wall" construction. From within outwards there is (1) Trichopièse, (2) wood ceiling, to which the Trichopièse is fastened and which in turn rests on the porous stone of the inside layer of the.walls, (3) sheet lead, $3 \mathrm{~mm}$. thick, (4) an air space, (5) a second wood ceiling, which is covered with (6) asphalt paper, (7) sea grass and (8) Korkstein.

The floor is the least satisfactory part of the construction. The floor of the old room had to be used. To prevent vibrations passing from board to board the joints were sawed through and the crevices thus made were filled with lead. The whole floor was then covered with a layer of lead, $3 \mathrm{~mm}$. thick, and over this a very thick $(1 \mathrm{~cm}$.) carpet has been placed. At times a second carpet is also used. Had the original floor been of marble or cement it is probable that the two layers (lead and carpet) would have been as satisfactory as the six layers of the walls.

The door is double. The outer part opens on the corridor. It is an ordinary door, made of wood, but accurately fitted with felt. The inner door is composed of three layers. The middle layer is wood, the inner or room layer is Trichopièse, and the outer layer is Korkstein. This inner door opens into the room. There is the usual air space between the two doors. The door is part of one of the long sides of the room.

Nearly opposite the door is a small rectangular window, 38 by $45 \mathrm{~cm}$. This opens into the small adjoining room to the south and is directly opposite the window in the roof. The roof window opens to admit light and air, but the opening is covered with a fine gauze screen to exclude insects and especially moths. When both windows are open the sun can get into all corners of the room and the room may be partially ventilated. With doors and windows open the room is thoroughly ventilated.

The sound stimuli may have their origin in or outside the sound room. If the source of the sound is in an adjoining room the apparatus is placed in a cabinet, isolated from the floor by a lead plate and felt, and covered with the same materials. This isolation still further decreases the chance of these noises or tones entering the room through floor, ceiling or walls except in the manner that is desired.

For experiments in which it is necessary to have the origin of the sound stimuli at a distance from the subject means are needed for conducting the sound into the room. For this reason a hole was bored through one of the walls and a copper tube inserted. This tube is fastened to a marble plate, which in turn is fastened to the second layer, porous stone, of the inner wall. The wood partition is here omitted and a plate of lead, $2.5 \mathrm{~cm}$. thick, is used for the outer part of the wall. To close the copper tube lead plugs were made, one of which is solid, a second has a single opening, $1.5 \mathrm{~cm}$. diameter, and the third has two open- 
ings, each $0.8 \mathrm{~cm}$. diameter. The solid lead plug serves to keep the room sound-proof if it is not necessary to conduct the sound from without; the second and third give opportunity of introducing one or two sound stimuli, respectively.

The room is fitted with electric light and wires for telephone and other electrical purposes.

The location of the window, on the southern side of the room, makes it possible to have the room lighted by the sun and a thorough ventilation may be secured in the intervals of a series of experiments. One thing has not been solved in the construction, viz., the ventilation of the room during a series of tests. The room is large enough to hold one person for, say, a half hour without discomfort from lack of oxygen, and the use of porous material in the construction may make it possible to remain a longer time without ill effect. ${ }^{2}$ For a series of tests on tones a half hour is sufficient time if we do not have to deal with a condition of the ear analogous to the adaptation of the eye. If time is needed for the "adaptation" of the ear perhaps some further scheme of ventilation may be required. On this point, the adaptation of the ear, we have no information and one of the possibilities of the room is the discovery of such adaptation.

When in the room, some, not all, persons experience peculiar sensations from the ear (drum?), corresponding to the sensations in slightly compressed air. There is a distinct feeling of pressure which is subjective and which disappears so soon as a sound is made, or sound stimuli are given.

The noiselessness of the room is shown by the fact that one hears a subjective buzzing, similar to but of less intensity than the buzzing produced by large doses of quinine. Many normal people can also hear their own heart sounds. It is true that their own heart sounds can be heard by some in rooms not noiseless, but this is not the case with many normal individuals except after very violent exercise. In the room a few swings of the

\footnotetext{
${ }^{2}$ On this point I failed to make inquiries.
}

leg or arm is often sufficient to make the heart sounds quite distinct. Other body noises may also be heard. If a movement of a few inches in extent is made, such as lightly brushing the foot over the carpet or a free movement of the arm, the sound is distinctly audible. So audible are these noises that one must be careful not to move when experiments are in progress. A further proof of the noiselessness of the room is to be found in the fact that a shell held to the ear does not appear to give forth any sound. The tones for which the shell is resonant are absent. It should be mentioned again here that the felt-like lining of the room effectually stops all sound reflection. Whatever sounds are produced or brought into the room are in this respect simple; they cease when the vibration reaches the wall.

To keep the room fresh and clean, in addition to the entrance of sunlight and fresh air, dust and other dirt are removed by a mechanical cleaner-the so-called compressed air cleaner-and it is disinfected by formalin vapor.

In experiments during the past three or four years the room has been used in its various conditions of evolution and in its final form has proved to be most satisfactory. For many years it will doubtless be a standard for the construction of similar rooms in other institutions.

Shepherd Ivory Franz

GEORGE WASHINGTON UNIVERSITY

Government Hospital FOR THE Insane

\section{SEVENTH INTERNATIONAL ZOOLOGICAL CONGRESS-SECTION OF PALEOZOOLOGY}

For the first time in the history of the International Zoological Congress, a section of paleozoology was organized and met during the Boston convention of the congress, August 1924. Early in the year a circular announcing the formation of this section was sent to paleontologists of this and other countries from the office of the organization chairman, Professor H. F. Osborn. ${ }^{1}$ This circular called attention to the unusual opportunity afforded

\footnotetext{
${ }^{1}$ Owing to Professor Osborn's absence in Egypt, many omissions in the sending of this circular occurred.
} 